\title{
The Monetary Transmission Mechanism and Inflation Targeting: A Regime-Switching VAR Approach for Canada
}

\author{
Ronald H. Lange ${ }^{1}$ \\ ${ }^{1}$ Economics Department, Laurentian University, Sudbury, Ontario, Canada, P3E 2C6 \\ Correspondence: Ronald H. Lange, Economics Department, Laurentian University, Sudbury, Ontario, Canada.
}

Received: January 27, 2016

Accepted: February 14, 2016

Available online: March 22, 2016

doi:10.11114/aef.v3i2.1338

URL: http://dx.doi.org/10.11114/aef.v3i2.1338

\begin{abstract}
This study employs a Markov-switching VAR with regime-dependent dynamics to assess the transmission mechanism of monetary policy in Canada. The regime-switching estimations divide the sample period stochastically into two continuous regimes that corresponds to the periods before and after explicit-inflation targeting in Canada. The empirical results indicate relatively large differences in both the innovation process due to the variance component of the VAR and the propagation mechanism due to the regime-dependent systematic component. The pre-targeting regime corresponds to much larger innovations in the macroeconomic variables and overall larger systematic responses of the macroeconomic variables to the innovation processes, suggesting a stronger monetary transmission mechanism in the regime. However, variance decompositions and counterfactual analysis suggest that monetary policy has become more responsive to fluctuations in output growth and inflation in the target regime. Overall, about 80 per cent of the variations in the monetary policy rate in the current regime can be explained by the systematic reactions of policy to output growth and inflation at the relevant policy horizons.
\end{abstract}

\section{JEL Classification: E44, E52}

Keywords: monetary transmission mechanism, regime switching, vector autoregessions

\section{Introduction}

Several countries, including Canada, adopted explicit-inflation targets in the early 1990s. In general, these countries have experienced noticeable reductions in the variability of output and inflation since adopting the targets. For example, since adopting inflation targets in 1991, Canada has experience a reduction in the standard deviations of quarterly (annualized) output growth and inflation of about 45 per cent and 30 per cent, respectively, relative to the previous two decades.

The important issue for policy makers is whether the reduced volatility of output and inflation is due to smaller, and less frequent, exogenous macroeconomic disturbances, or whether the propagation of the shocks has changed. In other words, output and inflation may have become less sensitive to the shocks because the monetary transmission mechanism has changed. Clarida, Gali, and Gertler (2000), for example, argue that monetary policy has become more responsive to fluctuations in output and inflation with the objective of minimizing the variability of output and inflation. In effect, this would partially compensate for the smaller effects that shocks have on output and inflation. This would especially be the case for a country that has adopted inflation targets. Alternatively, the economy may be less sensitive to shocks because consumers and firms have changed their behaviour and the organization of the economy may have changed in a way that has reduced the effects of given shocks on output and inflation.

The issue is important for policy makers because if the main cause of the increase in economic stability is a reduction in the size of the exogenous disturbances, then the economy may become more volatile if confronted with large successive shocks. However, if the increased stability is due to a more responsive monetary transmission mechanism, then it is possible the macroeconomic stability will last.

This study uses a Markov-switching vector autoregression (MS-VAR) with regime- dependent dynamics to study the monetary transmission mechanism in Canada. The VAR approach has been criticized because of its limitations to identify the systematic part of monetary policy, leaving just a reaction function in surprises (Clarida, Gali, and Gertler, 2000). However, this study allows for changes in the systematic behaviour of macroeconomic variables in response to 
unexpected shifts in the process of macroeconomic fluctuations. The aim is to investigate the potential structural changes in the transmission channels of Canadian monetary policy for economic activity and inflation.

To preview the results, the estimation captures two continuous regimes that correspond to the periods before and after explicit-inflation targeting in Canada. The pre-targeting regime corresponds to much larger innovations in the macroeconomic variables and overall larger systematic responses of the macroeconomic variables to the innovation processes, suggesting a stronger monetary transmission mechanism in the regime. However, variance decompositions and counterfactual analysis suggest that monetary policy has become more responsive to fluctuations in output growth and inflation in the current target regime.

The following section briefly outlines some previous research on the use of the regime-switching methodology to identify structural changes in monetary policy or changes in the monetary transmission mechanism. Section 3 discusses the regime- switching model with nonlinear dynamics. The data and preliminary specification of the model are presented in the following section. Section 5 presents some preliminary results on the variance and systematic components of the VAR, the regime-dependent impulse responses and variance decompositions, as well as a counterfactual analysis. The final section discusses the empirical results and interprets them from a policy perspective, and discuses some directions for future research.

\section{Previous Research}

In general, the empirical application of structural change to monetary policy is related to the large literature, surveyed by Christiano and Eichenbaum and Evans (1999), on the use of structural VAR's (SVAR) to estimate the monetary transmission mechanism. Some important contributions to this literature are Bernanke and Mihov (1998), Christiano, Eichenbaum and Evans (2005), and Smets and Wouters (2002). However, the most relevant strand of research for this study on structural change in the transmission of monetary policy is the application of the regime switching VAR methodology to the macroeconomy. Since the seminal work by Hamilton (1989) on U.S. business cycles, the Markov-switching technique been widely applied in various scenarios. Generally, most applications have been with autoregessive (AR) models. However, more recently, the technique has been applied to the simultaneous equation framework by using vector autoregessions (VAR) to study interest rates (e.g., Ang and Bekaert, 2002), exchange rates (e.g. Chen, 2006 and Soledad and Peria, 2002), and international and regional business cycles (e.g., Krolzig, 2001 and Krolzig and Toro, 2005), as well as other areas.

The comprehensive study by Sims and Zha (2006) on the U.S. economy is particularly important because it establishes a baseline for empirical research on macroeconomic switching. They develop an efficient Markov-Chain Monte-Carlo (MCMC) method for solving Markov-switching SVARs (MS-SVAR) identified with linear restrictions on each structural equation. In general, they allow residual variances and coefficients for all equations in the VAR to change between states in order to focus on nonlinearities that lead to a deterioration of goodness of fit and heteroskedasticity. They find that their best fit is the one that allows for no time variation in the coefficients of the policy rule or the private sector block of the model, but allows for the disturbance variances of the model to change among three states. Their best-fitting model among those that allow coefficients to change is one that constrains the changes to occur in the monetary policy equation, while coefficients in the other equations remain constant. These results are important for this study because they find more evidence of a stable transmission mechanism with unstable disturbance variances than of clear changes in model dynamics.

Rubio-Ramírez, Waggoner, and Zha (2005) find similar evidence for the European Monetary Union (EMU) using various MS-SVAR models to analyse whether monetary policy and the volatility of euro area macroeconomic variables have changed since the introduction of the EMU in 1993. They similarly find that the source of time variation embedded in euro area aggregate variables can be attributed to changes in shock variances and that the MS-SVARs based solely on time-varying shock variances are strongly favoured to models in which slope coefficients also change with the regime. They also find a stable and persistent post-1993 regime that is associated with low volatility of shocks to output, prices and interest rates, and that the output effects of monetary policy shocks are small and uncertain across regimes and models. They found that their results were robust to the various identification schemes for monetary policy.

Paolillo and Petragallo (2004) also use the MS-VAR methodology that allows for state-dependent, impulse response functions to analyse possible asymmetries in the business cycle transmission between US and Euro area; that is, whether the transmission channel depends on the state of the economy (low and high growth). They find strong evidence in favour of asymmetries in the transmission mechanism of the business cycle due to the interest rate differential and the Euro dollar exchange rate.

Some recent research on specific macroeconomies has found that state-dependent dynamics in regime-switching VARS are particularly useful for identifying structural changes in the monetary transmission mechanisms. For example, Gonzalez and Garcia (2006) found that there was a major structural change in the transmission mechanism of monetary 
policy in Mexico around the beginning of 2001, the date of formal adoption of the inflation targeting framework for the conduct of monetary policy. This structural change implied a less important role for fluctuations of the real exchange rate in the process of price formation and in the formation of inflation expectations, as well as a milder effect on the nominal interest rate. They found that the adoption of the inflation targeting framework involved a stronger reaction of the nominal interest rate to increases in the output gap and the inflation rate and that the nominal interest rate had a stronger effect on the real exchange rate.

Similarly for Japan, Fujiwara (2003, 2006) uses a MS-VAR with regime-dependent, impulse-response functions to study whether the effects of monetary policy has changed during 1990s and whether the zero bound of nominal interest rate may have had some distortional effects on macroeconomic dynamics. His regime-dependent impulse response functions suggest that there was a structural change in the 1990s and that the traditional interest-rate channel is not functioning and, therefore, the role of monetary expansion is now limited. However, Girardin and Moussa (2009) used a factor-augmented, Markov-switching VAR (MS- FAVAR) that included the information in 143 variables for factors on real activity, prices, the monetary base, and interest rates in Japan to find that the regime-dependent response of the output factor is three times as large in the post-1995 regime as in the pre-1995 regime, and that it is 50 per cent longer-lived. The response of the price factor, while slightly smaller is much longer-lived (up to nine months) than in the first regime. Overall, the non-neutrality of money and the price divergence in the pre-1995 regime that characterized the MS-VAR model in Fujiwara (2006) disappeared with the contribution of the information contained in the additional factors.

More recently, Herwartz and Lutkepohl (2014) use a quarterly MS-SVAR model for the U.S. with oil prices, output, the price level and a short-term interest rate to show that changes in the volatility of the residuals of a VAR model may be needed to obtain identifying information for structural shocks. For example, they show how identifying statistical information about monetary policy must be combined with economic restrictions to distinguish monetary policy shocks from oil-price shocks to obtain a meaningful interpretation of the monetary shocks. Similarly, Hubrich and Tetlow (2015) use a five variable MS-VAR for the U.S. with personal consumption expenditures, core CPI inflation, the federal funds rate, M2 growth, and a financial stress index to show that both variance and coefficient switching are needed to capture the linkage between financial stress and the macroeconomy. Important to the interpretation of the results in this study on Canada, they show that shifts in the transmission mechanism of monetary policy during periods of financial stress coincide with the regime changes in the innovation processes.

\section{Empirical methodology}

The studies on the EMU, Japan, and Mexico suggest that the Markov-switching model with nonlinear regime dynamics may provide some useful insights to whether there has been a structural change in the monetary transmission mechanism in a country like Canada that has adopted explicit inflation targets. This study adopts the Markov regime-switching methodology developed by Ehrmann, Ellison and Valla (2001, 2003). They use regime-dependent impulse response functions to trace out how fundamental disturbances affect the variables in the model, dependent on the regime. Their approach combines Markov-switching and identification in a two-stage procedure of estimation and identification. First, a Markov-switching unrestricted VAR model is estimated, allowing means, intercepts, autoregressive parameters, variances and covariances to switch. Estimation of the Markov-switching model uses the expected maximum likelihood technique of Hamilton (1990) because the recursive nature of the likelihood, stemming from the hidden Markov Chain, precludes likelihood maximization with standard techniques. Second, they identify the system by imposing restrictions on the parameter estimates to derive a separate structural form for each regime, from which it is possible to compute the regime-dependent impulse response functions.

More formally, the general Markov-switching vector autoregression model may be written as

$$
\begin{gathered}
\mathrm{X}_{\mathrm{t}}=\left[\begin{array}{c}
\mathrm{X}_{1 \mathrm{t}} \\
\cdots \\
\mathrm{X}_{\mathrm{mt}}
\end{array}\right]=\left[\begin{array}{c}
v_{1}+\mathrm{B}_{11} \mathrm{X}_{\mathrm{t}-1}+\cdots+\mathrm{B}_{\mathrm{p} 1} \mathrm{X}_{\mathrm{t}-\mathrm{p}}+\mathrm{A}_{\mathrm{i}} \mu_{\mathrm{t}} \\
\cdots \\
v_{\mathrm{m}}+\mathrm{B}_{1 \mathrm{~m}} \mathrm{X}_{\mathrm{t}-1}+\cdots+\mathrm{B}_{\mathrm{pm}} \mathrm{X}_{\mathrm{t}-\mathrm{p}}+\mathrm{A}_{\mathrm{m}} \mu_{\mathrm{t}}
\end{array}\right] \text { if }\left[\begin{array}{c}
\mathrm{s}_{\mathrm{t}}=1 \\
\cdots \\
\mathrm{s}_{\mathrm{t}}=\mathrm{m}
\end{array}\right], \\
\mu_{\mathrm{t}} \sim \mathrm{N}\left(0 ; \mathrm{I}_{\mathrm{K}}\right)
\end{gathered}
$$

where $K$ endogenous variables $X_{i}$ are explained by an intercept termv $v_{i}$, a K-dimensional autoregressive matrix $\mathrm{B}$ of order $\mathrm{p}$, and $\mathrm{A}_{\mathrm{i}} \mu_{\mathrm{t}}$. In this general specification, all parameters may switch between $\mathrm{m}$ regimes; that is there is coefficient switching, and hence, nonlinear dynamics. 
The intercepts $v_{\mathrm{i}}$ for $\mathrm{i}=1, \ldots, \mathrm{m}$ in equation (1) are simply the regime-weighted average of the means of the residuals

from the VAR. This specification has the advantage of allowing the mean intercept to smoothly approach a new level

after

the transition from one state to another. ${ }^{1}$ The $\mu_{\mathrm{t}}$ is a K-dimensional vector of normally distributed fundamental disturbances uncorrelated at all leads and lags. However, the fundamental disturbances are pre multiplied by a regime-dependent matrix $A_{i}$, so that the variance-covariance matrix $\Sigma_{i}$ of the residuals $A_{i} \mu_{i}$ is also regime-dependent:

$$
\Sigma_{i}=E\left(A_{i} \mu_{t} \mu^{\prime}{ }_{t} A_{i}^{\prime}\right)=A_{i} E\left(\mu_{t} \mu^{\prime}{ }_{t}\right) A^{\prime}{ }_{i}=A_{i} I_{K} A^{\prime}{ }_{i}=A_{i} A_{i}^{\prime},
$$

Allowing for variance switching is important to avoid biasing results toward the erroneous finding of coefficient switching since variance switching and parameter switching are rivals in explaining the data.

The description of the data-generation process is not completed by the observational equation (1). A model for the regime-generating process is needed to allow for inference about the evolution of regimes from the data. The special characteristic of the Markov-switching model is the assumption that the unobservable realization of regime $\mathrm{s}_{\mathrm{t}} \in\{1, \ldots, \mathrm{m}\}$ is governed by a discrete-time, discrete-state Markov stochastic process. Formally, the stochastic process is defined by the transition probabilities $\mathrm{p}_{\mathrm{ij}}$, where

$$
\mathrm{p}_{\mathrm{ij}}=\operatorname{Pr}\left(\mathrm{s}_{\mathrm{t}+1}=\mathrm{j} \mid \mathrm{s}_{\mathrm{t}}=\mathrm{i}\right), \sum_{\mathrm{j}=1}^{\mathrm{m}} \mathrm{p}_{\mathrm{ij}}=1 \forall \mathrm{i}, \mathrm{j} \in\{1, \ldots, \mathrm{m}\}
$$

More specifically, $\mathrm{s}_{\mathrm{t}}$ is assumed to follow an ergodic and irreducible m-state Markov chain of order one with the transition matrix

$$
P=\left[\begin{array}{cccc}
\mathrm{p}_{11} & \mathrm{p}_{12} & \ldots & \mathrm{p}_{1 \mathrm{~m}} \\
\mathrm{p}_{21} & \mathrm{p}_{22} & \ldots & \mathrm{p}_{2 \mathrm{~m}} \\
\cdots & \cdots & \ldots & \ldots \\
\mathrm{p}_{\mathrm{m} 1} & \mathrm{p}_{\mathrm{m} 2} & \ldots & \mathrm{p}_{\mathrm{mm}}
\end{array}\right]
$$

where $\mathrm{p}_{\mathrm{im}}=1-\mathrm{p}_{\mathrm{i} 1}-\ldots-\mathrm{p}_{\mathrm{i}, \mathrm{m}-1}$ for $\mathrm{i}=1, \ldots, \mathrm{m}$. By inferring the probabilities of the unobserved regimes conditional on an available data set, it is then possible to reconstruct the regimes. For an ergodic Markov chain, regime shifts are persistent if $p_{i j} \neq p_{i i}$ for $i \neq j$ and not permanent if $p_{i i} \neq 1$ for all $\mathrm{i}$. As shown by Ehrmann, Ellison and Valla (2003), regimes predicted by the transmission matrix must be highly persistent in order to have useful regime-dependent impulse functions.

The two components of the Markov-switching, intercept, autoregressive, heteroskedastic VAR model, or MSIAH(m)-VAR(p) in the terminology of Krolzig (1997), the Gaussian multivariate model (1) as the conditional data generating process and the Markov chain (3) as the regime generating process, are estimated using a likelihood-based statistical method. The maximization of the likelihood function of the MS-VAR entails an iterative technique to obtain estimates of the intercepts $v\left(s_{t}\right)$, autoregessive parameters $B\left(s_{t}\right)$, and variance-covariance matrices $\Sigma\left(s_{t}\right)$, and the transition probabilities $\mathrm{p}_{\mathrm{ij}}$ governing the Markov chain of the unobserved states. The maximum likelihood estimation is based on the implementation of the Expectation Maximization (EM) algorithm proposed by Hamilton (1990) for this class of models. Each iteration of the EM algorithm involves two steps. The expectation step involves a pass through the smoothing algorithm, using the estimated parameter vector for the VAR of the last maximization step in place of the unknown true parameter vector to infer the hidden Markov chain. In the maximization step, an estimate of the parameter vector is derived as a solution of the first-order conditions of the likelihood function, where the conditional regime probabilities are replaced with the smoothed probabilities derived in the last expectation step. These two steps are repeated until convergence is achieved for the maximum likelihood function.

Applying the EM algorithm gives estimates of the parameters associated with each regime, $\widehat{v}_{\mathrm{i}}: \widehat{\mathrm{B}}_{1 \mathrm{i}}, \ldots, \widehat{\mathrm{B}}_{\mathrm{pi}}: \widehat{\Sigma}_{\mathrm{i}}$ for $\mathrm{i}=$ $1, \ldots, \mathrm{m}$, the transition probability matrix $\hat{P}$, and the optimal inference of the hidden Markov chain $\hat{\xi}_{\mathrm{i}, \mathrm{t}}=\operatorname{Pr}\left(\mathrm{s}_{\mathrm{t}}=\mathrm{i}\right)$ for $\mathrm{i}=1, \ldots, \mathrm{m}$ and $\mathrm{t}=1, \ldots, \mathrm{T}$, where $\hat{\xi}_{\mathrm{i}, \mathrm{t}}$ is known as the smoothed probabilities. However, there is an identification problem because the EM algorithm only gives estimates of variance and covariance matrices $\left(\Sigma_{1}, \ldots, \Sigma_{\mathrm{m}}\right)$ and not the matrices $\left(A_{1}, \ldots, A_{m}\right)$. To identify these matrices, restrictions are imposed on the parameter estimates from the

\footnotetext{
${ }^{1}$ In contrast, a mean-switching vector autoregessive model has a multiplicative relationship between the VAR coefficients and the intercepts that allows for an immediate one-time, permanent jump in the process mean after a change in regime. This specification is more appropriate for discrete switching variables, such as GDP in studies of expansion and recession regimesin regime. This specification is more appropriate for discrete switching variables, such as GDP in studies of expansion and recession regimes.
} 
unrestricted VAR model (1). Since each matrix $A_{i}$ has $K^{2}$ elements to be identified, $K^{2}$ restrictions must be imposed. The identity $\mathrm{A}_{\mathrm{i}} \mathrm{A}_{\mathrm{i}}^{\prime}=\Sigma_{\mathrm{i}}$ from equation (2) imposes $\mathrm{K}(\mathrm{K}+1) / 2$ because of the symmetry of variance-covariance matrix $A_{i}$. The missing $K(K-1) / 2$ restrictions can be derived by imposing a recursive structure on the model so that the matrix $\mathrm{A}_{\mathrm{i}}$ is lower triangle and exactly identified. ${ }^{2}$ The matrix can be recovered from a Choleski decomposition of the matrix $\Sigma_{\mathrm{i}}$.

The regime-dependent impulse response functions describe the relationship between the endogenous variables and the fundamental disturbance within each Markov-switching regime. The regime-dependent impulse response functions are conditional on a given regime prevailing at the time of the disturbance and throughout the duration of the response. The validity of regime conditioning depends on the time horizon of the impulse response and the expected duration of the regime. As long as the time horizon is not excessive and, as mentioned above, the transition matrix predicts regimes which are highly persistent, then the conditioning is valid and regime-dependent impulse response function are considered a useful tool for analysis.

The general model contains $\mathrm{mK}^{2}$ regime-dependent impulse-response functions, corresponding to the reaction of $\mathrm{K}$ variables to $\mathrm{K}$ disturbances in $\mathrm{m}$ regimes. The regime-dependent impulse response function for regime $\mathrm{i}$ is

$$
\left.\frac{\partial}{\partial \mu_{\mathrm{k}, \mathrm{t}}} \mathrm{E}_{\mathrm{t}} \mathrm{X}_{\mathrm{t}+\mathrm{h}}\right|_{\mathrm{s}_{\mathrm{t}}=\ldots \mathrm{s}_{\mathrm{t}+\mathrm{h}}=\mathrm{i}}=\theta_{\mathrm{ki}, \mathrm{h}} \text { for } \mathrm{h} \geq 0,
$$

where the expected change in the endogenous variables $X_{i}$ at time $t+h$ to a shock to the kth fundamental disturbance at time $t$ is conditional on regime $i$. A series of $\mathrm{K}$-dimensional response vectors $\theta_{\mathrm{ki}, 1}, \ldots, \theta_{\mathrm{ki}, \mathrm{h}}$ predict the response of the endogenous variables. Estimates of the response vectors can be derived by combining the unrestricted parameter estimates of the reduced-form Markov-switching vector autoregression B in equation (1) with the estimate of the matrix $\widehat{\mathrm{A}}_{\mathrm{i}}$, which is obtained through the identification restrictions.

The first response vector measures the impact of the Kth fundamental disturbance on the endogenous variables. A shock to the Kth fundamental disturbance implies the initial disturbance vector is $\mu_{o}=(0, \ldots, 0,1,0, \ldots, 0)$, where a vector of zeros is apart from the Kth element which is one. Premultiplying this vector by the estimated regime-dependent matrix $\widehat{\mathrm{A}}_{\mathrm{i}}$ as in equation (1) gives the impact impulse responses. The remaining response vectors can be estimated by solving forward for the endogenous variables in equation (1). The equations (6) and (7) below show the solution linking the estimated response vectors with the estimated parameters.

$$
\begin{gathered}
\hat{\theta}_{k i, 0}=\widehat{A}_{i} \mu_{0} \text {, and } \\
\widehat{\theta}_{k i, h}=\sum_{j=1}^{\min (h, p)} \widehat{B}_{j i}^{h-j+1} \widehat{A}_{i} \mu_{0} \text { for } h>0 .
\end{gathered}
$$

Since direct sampling is difficult with a Markov chain, the confidence intervals around the impulse responses are computed using Gibbs sampling (Gelfand and Smith, 1990) for a Markov Chain Monte Carlo (MCMC) algorithm to deal with the posterior distribution. The Gibbs sampler can generate a Markov chain of samples of observations which can approximate the joint probability distribution of the random variables in the model. Since each sample is correlated with nearby samples, the samples from the beginning of the chain, called the "burn-in period," may not accurately represent the desired unconditional distribution. Consequently, a certain number of early draws are dropped out of the simulation to obtain the unconditional posterior distribution in the limit.

\section{Data and preliminary specification}

The estimation period is from 1972 to $2010^{3}$ and the frequency is quarterly. ${ }^{4}$ The macroeconomic variables for the estimations include the overnight financing rate (ron) as the monetary policy rate, ${ }^{5}$ output growth based on GDP in

\footnotetext{
${ }^{2}$ The conditional impulse response functions can be derived from a variety of identification schemes, which is the subject of the structural vector autoregression literature, such as Sims (1980), Blanchard and Quay (1989), King, Plosser, and Stock (1991), and Galí (1992).

${ }^{3}$ The beginning of the sample coincides with the introduction of flexible exchange rates.

4. Although a monthly frequency would be preferable for a study on monetary policy, monthly data on industrial production for Canada only begins in 1987 and data on monthly GDP only begins in 1997. The quarterly data is need for a measure of economic activity and the quarterly GDP deflators for both Canada and the U.S. are used to construct a measure of the real exchange rate.
} 
2002 chain- linked dollars (output), the consumer price index for all items (inflation), and the real exchange rate (pfx). Output growth and inflation rate are the log-difference over 1-quarter and scaled by 100 so that changes can be interpreted as the 1-quarter percentage change. The real exchange rate is defined as the Canada-US nominal exchange rate (e.g., price of a unit of US currency in terms of Canadian currency) multiplied by the ratio of the US GDP deflator to the Canadian GDP deflator. Since the log of the real exchange rate does not increase exponentially like real GDP and the consumer price index, it is simply multiplied by 100 so that a change can be interpreted as a percentage change.

Sims (1980) and other related research recommend against differencing even if the variables are not stationary because the main purpose of a study using VAR is not to determine the parameter estimates but to know the inter-relationship among the variables. In this case, differencing should not be employed because it throws away important information concerning the comovements in the data. However, in a later study, Sims, Stock and Watson (1990) also show that independently of the order of integration of the variables, one can get a consistent estimation of coefficients. Since this study focuses on the systematic reactions of monetary policy to the target variables, such as output growth and inflation, rather than to the output and price levels, the size of the coefficients and parameter consistency is important.

The four macroeconomic variables, the minimum need for a small scale VAR of an open economy, are ordered as $\mathrm{X}=$ [output, inflation, ron, $\mathrm{pfx}$ ]. The Choleski identification consists of ordering the variables from the most exogenous to the most endogenous variables and from the slow-moving to fast-moving variables in the system. Consequently, inflation responds to output growth in the previous quarter, the monetary policy rate responds to both output growth and inflation, and the exchange rate responds to all variables.

Augmented Dickey-Fuller tests for a unit root easily reject non-stationarity for the 1-quarter growth rates of output and inflation at the 95 per cent level, while non- stationary cannot be rejected for the overnight policy rate and for the log of the exchange rate. The null of a unit root in either variable is hard to reject at conventional significance levels because of the persistence of both series and the well- known low power of unit root tests. However, the non-stationary result for the monetary policy rate appears to be mainly an artifact of the short estimation period and may reflect economic disequilibrium or the lack of a constant nominal anchor over part of the estimation period, especially during the 1970s and early-1980s. ${ }^{6}$ In fact, non-stationarity can be rejected at the 95 per cent level for the monetary policy rate on a shorter sample period beginning in 1982.

An issue of paramount difficulty in specifying Markov-switching models is the choice of the number of lags and regimes. The choice of lag length for the VAR was guided by the Akaike Information, Hannan-Quinn and the Schwarz Bayesian Criteria. They choose 3, 2, and 1 lags respectively. In light of the large number of parameters to be estimated, the choice of 2 lags seems appropriate. The likelihood-ratio test statistic for testing the number of regimes is well known not to posse an asymptotic $\chi^{2}$ distribution because of the existence of a nuisance parameter under the null hypothesis. In the spirit of Krolzig (1997), preliminary testing with the general-to-specific approach to econometric modelling was conducted using a univariate ARMA analysis on each of the macroeconomic time series. Generally, the results are quite mixed with the Schwartz information criterion choosing two regimes for all variables and the Akaike criterion choosing three regimes for the overnight rate, and four regimes for the inflation rate and output growth.

However, preliminary estimations with a 3-regime VAR consistently chose a very high-variance regime that occurred during the 4-quarter period from 1980:2 to 1981:1 when the second oil-price shock was working itself through the economy. The very high-variance regime also coincides with regime 3 for the United States in Sims and Zha (2006), which they considered to be an outlier period when monetary policy was targeting monetary aggregates, not interest rates, and not to represent a permanent shift to a new type of behaviour. As mentioned earlier, Ehrmann, Ellison and Valla (2001) emphasize that regime-dependent impulse response functions are conditional on the regime prevailing at the time of the disturbance and throughout the duration of the responses. This concept is valid only when each regime is persistent. Consequently, since the forecast horizons used for the impulse response functions and variance decompositions are for sixteen quarters, the estimations in this study are for two regimes.

\section{Empirical results}

\subsection{Macroeconomic switching regimes}

The MSIAH(2)-VAR(2) model requires the estimation of a $4 \times 4$ matrix with 64 autoregressive parameters, a column of 4 intercept terms for each of the 2 regimes, a matrix of 4 variances and 6 covariances for each regime, and 2 independent transition probabilities, for a total of 94 parameters. Since the likelihood function for regime-switching

\footnotetext{
${ }^{5}$ Armour et al. (1996) find that innovations in the overnight rate, derived using a Choleski decomposition, were consistent with intended policy actions as described in the Bank of Canada's Annual Reports since the early 1960s.

${ }^{6}$ The assumption of a random walk may also not apply if a lower bound exists at low levels of interest rates, which has been the situation over the last few years of the sample period.
} 
models is well-known to have a large number of local maximums in finite samples, model selection for the parameter estimates is for the highest (mean) log-likelihood value.
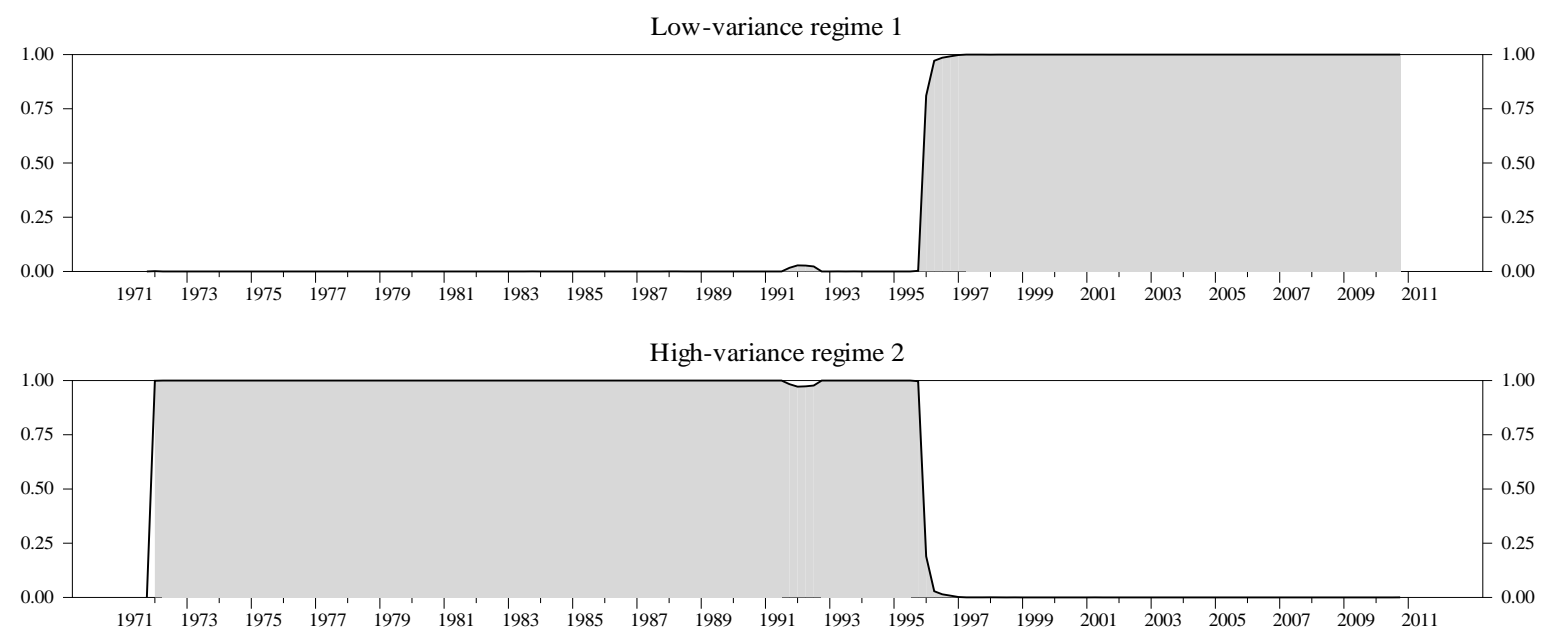

Figure 1. Regime Probabilities

Figures 1 indicates that the regimes are almost perfectly classified with probabilities being relatively close to zero or one. The regime estimation captures a clear structural break in 1996Q1 by stochastically dividing the sample from 1972Q1 to 2010Q4 into 2 continuous regime. Regime 2 is a high-variance regime that will be used to characterize the pre-inflation target period and regime 1 is a low-variance regime that will be used to reflect the explicit-inflation target regime. The break is stochastically determined, which means that it is possible the pre-target regime could switch back again someday in the future. Although the inflation targets were officially adopted by the Bank of Canada and the Government of Canada in 1991, it appears that it took a few years for the monetary transmission mechanism to adapt to the new monetary environment.

\subsection{Hypotheses Testing}

Table 1 presents the likelihood-ratio (LR) tests for overall restrictions on the reduced-form of the regime-switching VAR that include the transition probabilities. With the exception of the exchange rate, the null hypotheses of one regime can be rejected at the 5 per cent level of significance for all restrictions, suggesting important changes over the two regimes in both the variance-covariance matrix $\left(\Sigma_{\mu}\right)$ and the systematic component of the VAR model $(v+$ $\left.\mathrm{B}_{1} \mathrm{X}_{\mathrm{t}-1}+\ldots+\mathrm{B}_{\mathrm{k}} \mathrm{X}_{\mathrm{t}-\mathrm{k}}\right)$, where $v$ is a vector of constants and the $\mathrm{Bs}$ are matrices of coefficients for $\mathrm{K}$ endogenous variables in equation (1). Thus, not only has the variances of the innovations $\mu_{t}$ changed significantly, but the propagation of the shocks themselves has changed between the regimes. In particular, the restrictions on the monetary policy coefficients across equations indicate important changes in the systematic responses of policy to output and inflation, and the restrictions on the coefficients for output and inflation equations to the policy rate across regimes also indicate important nonlinear dynamics in the Canadian macroeconomy. Overall, there have been significant changes in the monetary transmission mechanism in Canada. These results differ noticeably from the results for the U.S by Sims and Zha (2006), who find more evidence of a stable transmission mechanism with unstable disturbance variances than of clear changes in model dynamics.

The restriction reported at the top of Table 1 that only the covariance matrix has changed, while the autoregressive parameters remain the same across the two regimes, yield exactly the same stochastic break point with continuous regimes as in Figure 1. However, the restriction that only the coefficients remain the same across the regimes does not reveal the well-defined policy regimes. This suggests that the regime shifts in the transmission mechanism of monetary policy coincide with regime changes in the innovation processes. As suggested by Hubrich and Tetlow (2015), it appears that changes in the volatility of the macroeconomic variables induced concomitant changes in the operation of monetary policy. The flexibility of (unrestricted) variance switching appears to "push out" coefficient switching as a source of time variation in the data. Although the causality cannot be formally tested, it suggest that transition mechanism of monetary policy adapted to the explicit inflation-targeting regime in 1996 after the reduction in the volatility of the macroeconomy took place and not as soon as the inflation targets were adopted in 1991. As a result, 
coefficient switching turns out to be help helpful in explaining the Canadian data even in the presence of unrestricted variance switching, which is a quite noteworthy result in itself.

Table 1. VAR regime restrictions

\begin{tabular}{lccc}
\hline restrictions & number & LR test & $\frac{\text { critical value }}{\left(\chi^{2} \text { at 5\%) }\right.}$ \\
\hline covariance matrix & 10 & 164.57 & 18.31 \\
all coefficients & 36 & 106.07 & 49.80 \\
all lagged coefficients & 32 & 92.49 & 43.77 \\
lagged output coefficients & 8 & 24.08 & 15.51 \\
lagged inflation coefficients & 8 & 44.11 & 15.51 \\
lagged policy rate coefficients & 8 & 24.19 & 15.51 \\
lagged pfx coefficients & 8 & 0.66 & 15.51 \\
\hline
\end{tabular}

Notes: Null hypothesis for each test is one regime versus two regimes with the transition probabilities included for each test.

Table 2 presents the values of the equation variances in the two regimes and test statistics for the restriction of equal variances of the innovations $\mu_{\mathrm{t}}$ for the equations. The p-values indicate that the regime-switching estimation captures conditional heteroskedasticity in the form of Markov switching in the scale $\sigma^{2}\left(s_{t}\right)$ of the variances for the output, policy rate, and exchange rate equations. Consequently, the error terms for theses equations switch discretely between low- and -high variance regimes. However, the difference in the variances of inflation in the two regimes is not statistically significant. The variance of output is about three times larger in regime 2 than regime 1 and the policy rate was much more volatility in regime 2 . The greater volatility of the policy rate is not surprising since monetary policy responded to the inflation triggered by the supply-side shocks in the mid-1970s and early-1980s, as well as the recession in the early-1980s. Overall, the greater variances for output and the policy rate suggest that output and monetary policy shocks were relatively more important in regime 2 than in regime 1.

Table 2. Variance restrictions

\begin{tabular}{lcccc}
\hline equation variance & regime 1 & regime 2 & $\chi^{2}$ & p-value \\
\hline output variance & 0.18 & 0.57 & 22.34 & 0.00 \\
inflation variance & $(5.81)$ & $(8.12)$ & & 0.47 \\
policy rate variance & 0.22 & 0.26 & 0.51 & 0.00 \\
pfx variance & $(4.13)$ & $(7.69)$ & & \\
& 0.07 & 1.73 & 52.30 & 0.00 \\
\hline
\end{tabular}

Notes: Terms in brackets are t-statistics

Table 3 presents test statistics for restrictions on specific monetary policy coefficients in the equations for output, inflation, and the policy rate. More specifically, the p-values indicate important changes in the systematic responses of monetary policy to output and inflation in the two regimes. The contemporaneous and lagged policy responses to output is about three time larger in regime 2 , about the same size as the difference in the variances of output growth for the two regimes in Table 2. Similarly, the policy response to inflation is also very large in regime 2. However, the inflation coefficients are very small and negative in regime 1 . This suggests a dramatic change in the systematic response of monetary policy to inflation. Since policy has pursued a forward-looking policy by responding to aggregate demand shocks, it has not had to respond to inflation shocks in regime 1. In essence, the monetary authority seems to have achieved credibility by explicitly adopting inflation targets.

The sum of the lagged coefficients on the policy rate in the equation for output growth indicates that the reactions of output growth to the policy rate is about five times larger in regime 2 . The restriction on the sum of lagged coefficients on the policy rate in the equation for inflation in the two regimes can easily be rejected with a very high p-value $(0.42)$. The large p-value for the sum of the lagged coefficients on the policy rate in the inflation equation in regime $1(0.51)$ 
and the very small, negative sum of lagged coefficients for inflation in the equation for the policy rate indicate, as mentioned above, a dramatic change in the current behaviour of inflation to the policy rate and the Bank of Canada responses to changes in inflation.

Table 3. Systematic monetary response and transmission restrictions

\begin{tabular}{|c|c|c|c|c|}
\hline$\underline{\text { coefficients }}$ & regime 1 & regime 2 & $\chi^{2}$ & p-value \\
\hline policy rate to output & $\begin{array}{c}0.25 \\
(0.00)\end{array}$ & $\begin{array}{c}0.84 \\
(0.00)\end{array}$ & 11.59 & 0.02 \\
\hline policy rate to inflation & $\begin{array}{l}-0.08 \\
(0.00)\end{array}$ & $\begin{array}{c}0.45 \\
(0.01)\end{array}$ & 12.83 & 0.00 \\
\hline output to policy rate & $\begin{array}{l}-0.03 \\
0.77)\end{array}$ & $\begin{array}{l}-0.14 \\
\quad(0.00)\end{array}$ & 10.89 & 0.00 \\
\hline inflation to policy rate & $\begin{array}{c}0.01 \\
(0.51)\end{array}$ & $\begin{array}{c}0.04 \\
(0.00)\end{array}$ & 1.75 & 0.42 \\
\hline
\end{tabular}

Notes: Terms in brackets are p-values for chi-squared tests on the significance of the lagged coefficients.

Overall, the tests of the restrictions in Tables 1 and 2 indicate relatively large changes in the variances and the systematic component of the VAR between the two regimes. The tests of the restrictions on the monetary policy rate in the output and inflation equations and on output and inflation in the policy rate equation in Table 3 indicate relatively large changes in the overall monetary transmission mechanism in the two regimes, mainly due to a change in the systematic behaviour of monetary policy.

\subsection{Impulse response functions}

The impulse responses from the 2-regime VAR in Figures 2 to 5 allow for a comparative analysis of the dynamic relationship among the macroeconomic variables to innovations in each variable for the two regimes. The impulse response functions are presented over a 16-quarter horizon. The confidence bands are displayed around the point estimates of the impulse response functions, ${ }^{7}$ where "significant" for a response means statistically different from zero, which corresponds to the case where the error confidence bands of the response function lie on one side of the $\mathrm{x}$ - axis. In order to facilitate a visual comparison of regime-dependent behaviour, the innovations are not standardized to equal 1-standard deviations. However, the graphs in each row are standardized to ensure that small responses are not inflated. Since the regimes in Figure 1 derived by the Markov switching estimation are long-lived and distinct, or continuous in nature, it is appropriate to compare the impulse responses between the different regimes as the analysis on the structural break (Ehrmann, Ellison and Valla (2003).

Figure 2 presents the impulse responses to innovations in the growth of real GDP of about 50 basis points in regime 1 and 75 basis points in regime 2 . The inflation response is significant and about the same size by the second and third quarters in both regimes, in line with conventional views about the effects of output growth on inflation. However, the response of the monetary policy rate differs noticeably, with an increase of about 20 basis points by the third quarter in regime 1, compared to a response of over twice the size in regime 2 . The responses of the exchange rate are insignificant in both regimes.

\footnotetext{
7. As described in Section 3.1, the error bands for the impulses responses are calculated from 5,000 random draws of the covariance matrix from the estimated VAR and computed using the Markov-Chain Monte-Carlo technique with 2,000 "burn in" draws for the Gibbs sampling.
} 

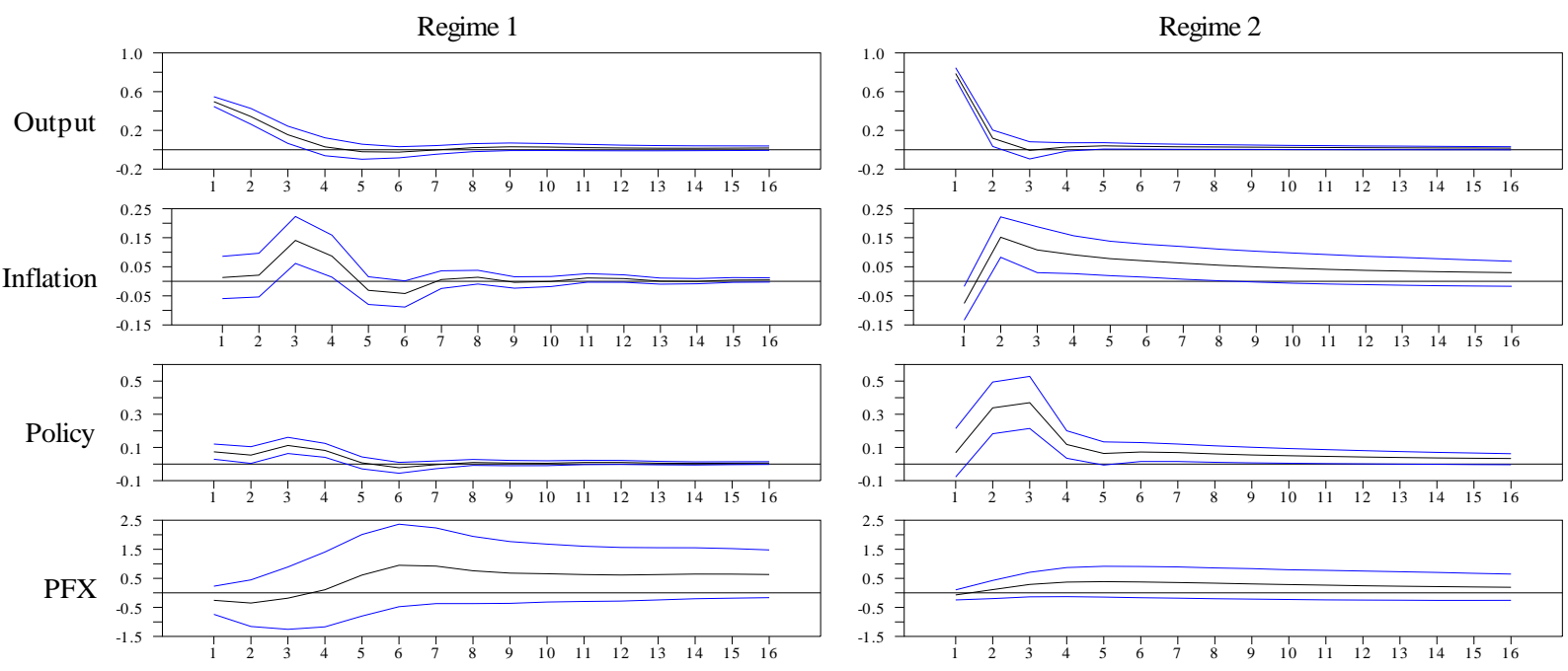

Figure 2. Shocks to Output
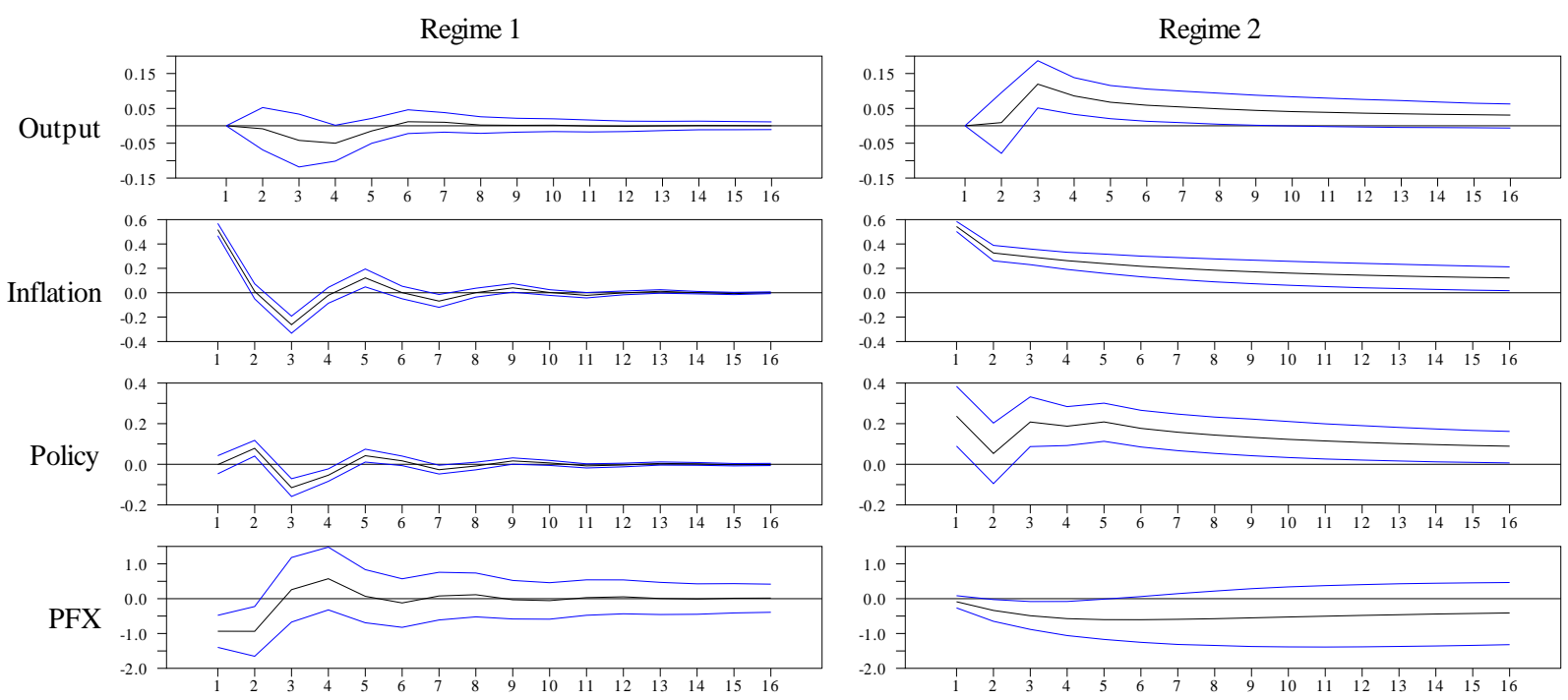

Figure 3. Shocks to Inflation

Figure 3 presents impulse responses to innovations in the inflation of about 50 basis points in both regimes. The monetary policy response in regime 2 is much larger and lasts for the 16-quarter forecast horizon. In contrast, the response in regime 1 is relatively small and insignificant over most of the horizon, suggesting that monetary policy may have become more forward looking in the current regime 1 by reacting to the inflationary pressures embedded in output growth or the output gap reflected in a Phillips-curve relationship so that it does not have to directly react to inflation shocks.

The reactions of output growth and inflation to innovations in the monetary policy rate of about 30 basis points in regime 1 and over 125 basis points in regime 2 are presented in Figure 4. The much smaller policy shock in regime 1 triggers a significant decline in output growth by about the fourth quarter and inflation by the sixth quarter, in line with the Bank of Canada's view about the monetary transmission mechanism in Canada. ${ }^{8}$ However, the much larger policy innovation in regime 2 does not trigger a significant decrease in output growth or inflation over the forecast horizon.

\footnotetext{
8. Conventional wisdom is that monetary policy in Canada has a maximum effect on output in about 4-to-6 quarters and an important effect on inflation in about 6-to-8 quarters. (See Bank of Canada website, 2010.)
} 
The increase in the policy rate in regime 1 also triggers an appreciation of the exchange rate (decrease in the price of foreign currency) that last over the forecast horizon.
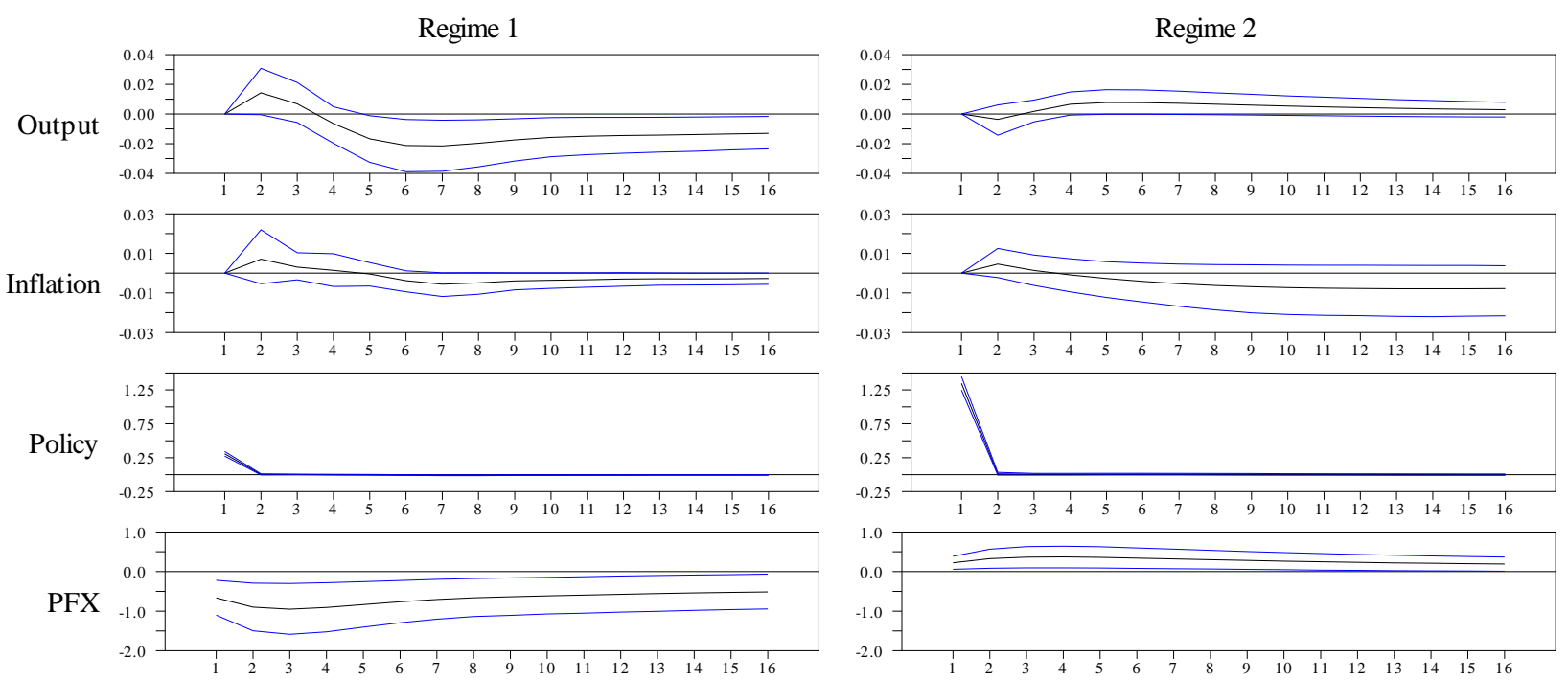

Figure 4. Shocks to Policy

Figure 5 presents the impulse responses for innovations in the exchange rate. The depreciation leads to an increase in output growth by about the fourth quarter in both regimes that lasts for most of the horizon. Overall, the impulse responses reflect the results of the hypothesis testing in Tables 1 to 3, with both larger innovations in the macroeconomic variables and larger systematic responses of the macroeconomic variables to the innovation processes in the pre-target regime 2 .
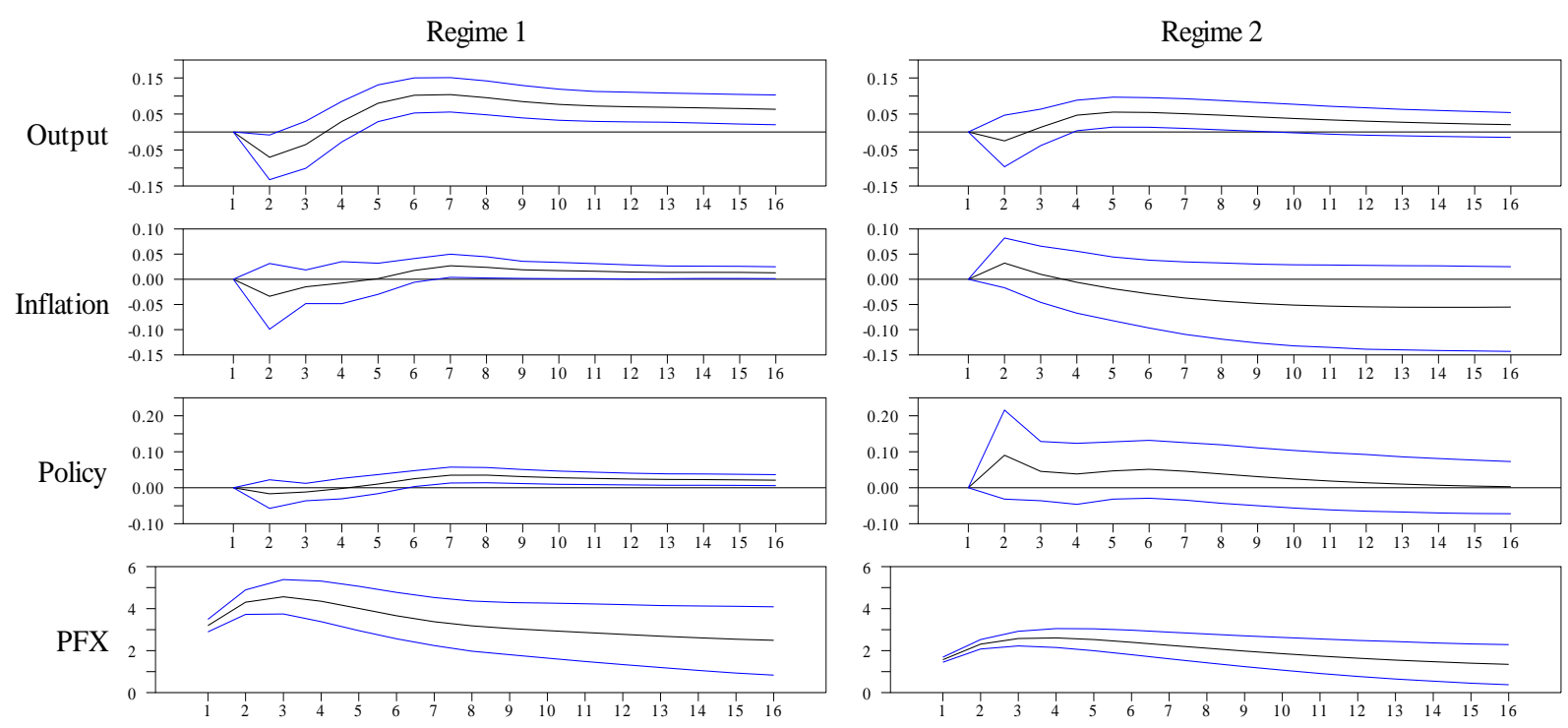

Figure 5. Shocks to PFX

\subsection{Variance decompositions}

The impulse responses presented in the preceding section produce a moving average representation of the point estimates of the VAR as the responses of the system to particular initial shocks. The error decomposition methodology is a useful complementary metric because it shows whether these impulse responses explain a meaningful amount of the variable. It decomposes the forecast error variance into the part due to each of the innovation processes. Table 4 presents the variance decompositions for both a 1-regime VARwith regime-independent dynamics and a 2-regime VAR with regime-dependent dynamics. The variance decompositions most relevant for the monetary transmission mechanism are the 4-quarter horizon for output growth and 8-quarter horizon inflation are presented in bold. 
In the upper panel for the 1-regime VAR, a 1-standard error innovation of 1.07 per cent in the policy rate explains about 1.3 per cent of the variation in the growth of output at the 4-quarter horizon and about 3.4 per cent of the variation in inflation at the 8-quarter horizon. Standard- error innovations of 69 per cent in output growth and 59 per cent in inflation explain slightly over 20 per cent of the variations in the policy rate at these horizons.

Table 4. Variance decomposition

\begin{tabular}{lccccc}
\hline variable & horizon & output & inflation & policy rate & PFX \\
\hline \multirow{4}{*}{ output } & \multicolumn{5}{c}{1 -regime VAR } \\
& 1 & 100.0 & 0.0 & 0.0 & 0.0 \\
\multirow{4}{*}{ inflation } & 4 & 96.5 & 1.8 & $\mathbf{1 . 3}$ & 0.4 \\
& 8 & 93.0 & 2.0 & $\mathbf{2 . 7}$ & 2.3 \\
& 1 & 0.3 & 99.7 & 0.0 & 0.0 \\
policy rate & 4 & 8.9 & 89.7 & $\mathbf{0 . 9}$ & 0.6 \\
& 8 & 13.3 & 82.4 & $\mathbf{3 . 4}$ & 0.9 \\
& 1 & 0.4 & 2.5 & 97.0 & 0.0 \\
PFX & 4 & $\mathbf{2 2 . 0}$ & $\mathbf{1 1 . 4}$ & $\mathbf{6 6 . 7}$ & 0.0 \\
& 8 & $\mathbf{3 2 . 6}$ & $\mathbf{2 0 . 3}$ & $\mathbf{4 7 . 1}$ & 0.0 \\
& 1 & 0.5 & 8.9 & 0.3 & 90.4 \\
& 4 & 0.1 & 13.8 & 1.0 & 85.6 \\
& 8 & 0.2 & 10.1 & 1.0 & 88.1 \\
\hline
\end{tabular}

low-variance regime 1 with regime-dependent dynamics

\begin{tabular}{lccccc}
\hline output & 1 & 100.0 & 0.0 & 0.0 & 0.0 \\
& 4 & 86.7 & 4.4 & $\mathbf{2 . 4}$ & 6.5 \\
inflation & 8 & 71.7 & 8.0 & $\mathbf{4 . 3}$ & 16.0 \\
& 1 & 0.1 & 99.9 & 0.0 & 0.0 \\
policy rate & 4 & 6.1 & 93.5 & $\mathbf{0 . 0}$ & 0.8 \\
& 8 & 6.7 & 91.7 & $\mathbf{0 . 0}$ & 1.5 \\
& 1 & 6.5 & 0.1 & 93.4 & 0.0 \\
\hline output & 4 & $\mathbf{4 9 . 8}$ & 12.7 & $\mathbf{2 2 . 6}$ & 14.9 \\
& 8 & 32.5 & $\mathbf{2 9 . 5}$ & $\mathbf{7 . 5}$ & $\mathbf{3 0 . 6}$ \\
\hline \multirow{4}{*}{ inflation } & high-variance regime & 2 with regime-dependent dynamics & \\
& 1 & 100.0 & 0.0 & 0.0 & 0.0 \\
& 4 & 88.5 & 1.1 & $\mathbf{9 . 9}$ & 0.5 \\
policy rate & 8 & 79.9 & 2.8 & $\mathbf{1 5 . 9}$ & 1.4 \\
& 1 & 2.6 & 97.4 & 0.0 & 0.0 \\
& 4 & 6.8 & 92.8 & $\mathbf{0 . 1}$ & 0.1 \\
& 8 & 6.8 & 92.8 & $\mathbf{0 . 1}$ & 0.3 \\
& 1 & 0.2 & 3.1 & 96.7 & 0.0 \\
\hline
\end{tabular}

Notes: Each entry is the percentage of the variance forecast at the specified forecast horizon. Bold values for the 4- and 8 -quarter horizons are used to indicate the relevant policy horizons for inflation and output growth. 
The middle panel presents the variance decompositions for innovations in regime 1. ${ }^{9}$ A 1-standard-error innovation in the policy rate is now only 30 per cent and explains 2.4 per cent of the variation in output growth at the 4-quarter horizon in regime 1, but does not explain any of the variation in quarterly inflation. The lack of a response of inflation to the monetary policy rate is consistent with the small, negative coefficients on the policy rate in the inflation equation in Table 3. The negligible response suggests that the Bank of Canada has managed to control inflation within the narrow inflation bands without responding directly to inflations shocks. The most interesting results are the systematic policy responses to 1-standard-error innovations of 42-per cent in output growth and 46-per cent in inflation. The responses to the innovations in output growth and inflation explain about 50 per cent of the variation in the policy rate at the 4-quarter horizon and about 30 per cent of the rate at the 8-quarter horizon, respectively. This is consistent with the view that monetary policy has become more forward-looking in the recent period with the adoption of inflation targets. However, about 30 per cent of the variation in the policy rate can also be explained by variations in the exchange at the 8-quarter horizon in regime 1, consistent with Lange (2013) who finds that monetary policy has responded in the past to large variations in the exchange rate.

The bottom panel of Table 4 presents the variance decompositions for the high-variance regime 2. A 133-per cent standard-error innovation in the policy rate in that regime explains almost 10 per cent of the variation in output growth and virtually none of the variation in inflation. This suggests that the relatively high and volatile inflation of the 1970s and 1980s that was triggered by supply-side shocks was brought down with a monetary policy focused on aggregate demand. An innovation in output growth at 74 per cent is much larger than in regime 1, but only explains about 15 per cent of the variation in the policy rate at the 4-quarter horizon. However, the larger innovation in inflation at 52 per cent explains about 24 per cent of the variation in the policy rate, almost the same amount as in regime 1. Instead, a relatively large portion of the variations of the policy rate at the policy-relevant horizons in region 2 are due to idiosyncratic variations that are unrelated to variations in output and inflation. They amount to 75 per cent at the 4-quarter horizon and 55 per cent at the 8-quarter horizon. Overall, there was a much larger effect of innovations in monetary policy on output growth in regime 2 .

\subsection{Counterfactual Analysis}

The variance decompositions in the previous section establish that the Canadian economy's response to interest rate fluctuations has changed between the two regimes. The decompositions quantify the varying systematic responses of monetary policy and of output growth and inflation, but they do not distinguish whether the change in the transmission of monetary shocks could result from a change in the systematic behaviour of the central bank or variations in the innovations themselves. For example, in Table 2, can the reduced variation in output, inflation and interest rates be explained by the smaller variability of the shocks in regime 1 or by the mechanism that propagates the innovations? In order to disentangle the two potential sources of variation, that is, whether they are due to the innovations themselves or to the propagation of the innovations, a counterfactual analysis is carried out on the variance decompositions by allowing for regime-dependent innovations, but holding regime dynamics constant for the two regimes.

Table 5 presents the variance decompositions for the regime-constant or -independent impulse-response functions for the regimes. The variance decompositions for a 1-standard error innovation in the policy rate in regime 1 for output growth and inflation at the 4- and 8-quarter horizons, respectively, are relatively small and of similar size to those reported in Table 4, suggesting that most of the variations in output growth and inflation are due to the innovation in the policy rate itself. However, the decomposition for an innovation in output growth at the 4-quarter horizon suggests that about 35 per cent of the variation in the policy rate in regime 1 is due to the innovation in output. The decomposition in Table 5 suggests that the remaining portion of the variation of 50 per cent, or about 15 per cent, is due to the regimedependent response of the policy rate to output growth. Similarly, a comparisons of variance decompositions of the policy rate for inflation at the 8-quarter horizon in Tables 4 and 5 suggest about 20 percent the variance in inflation can be explained by the size of the regime-dependent innovation in inflation and about 10 per cent by regime-dependent policy response Thus, a large portion of the systematic responses of monetary policy to innovations in output growth and inflation in regime 1 are regime dependent.

\footnotetext{
9. Since the restriction tests in Table 2 indicate that the systematic responses of the exchange rate have been constant across the regimes, the variance decompositions for the exchange rate are not presented.
} 
Table 5. Variance decompositions with constant dynamics

\begin{tabular}{|c|c|c|c|c|c|}
\hline variable & horizon & output & inflation & policy rate & PFX \\
\hline \multicolumn{6}{|c|}{ low-variance regime 1 with constant dynamics } \\
\hline \multirow[t]{3}{*}{ output } & 1 & 100.0 & 0.0 & 0.0 & 0.0 \\
\hline & 4 & 91.9 & 3.5 & 1.4 & 3.3 \\
\hline & 8 & 71.3 & 6.7 & 4.4 & 17.5 \\
\hline \multirow[t]{3}{*}{ inflation } & 1 & 1.4 & 98.6 & 0.0 & 0.0 \\
\hline & 4 & 6.1 & 93.4 & 0.0 & 0.4 \\
\hline & 8 & 7.5 & 91.7 & 0.2 & 0.7 \\
\hline \multirow[t]{3}{*}{ policy rate } & 1 & 5.4 & 0.5 & 94.1 & 0.0 \\
\hline & 4 & 33.9 & 15.3 & 49.6 & 1.3 \\
\hline & 8 & 43.7 & 20.7 & 33.8 & 1.8 \\
\hline \multicolumn{6}{|c|}{ high-variance regime 2 with constant dynamics } \\
\hline \multirow[t]{3}{*}{$\overline{\text { output }}$} & 1 & 100.0 & 0.0 & 0.0 & 0.0 \\
\hline & 4 & 92.2 & 0.2 & 7.4 & 0.2 \\
\hline & 8 & 82.2 & 0.6 & 16.7 & 1.5 \\
\hline \multirow[t]{3}{*}{ inflation } & 1 & 2.8 & 97.2 & 0.0 & 0.0 \\
\hline & 4 & 6.6 & 91.4 & 1.9 & 0.1 \\
\hline & 8 & 8.3 & 87.8 & 3.8 & 0.2 \\
\hline \multirow[t]{3}{*}{ policy rate } & 1 & 0.2 & 4.4 & 95.6 & 0.0 \\
\hline & 4 & 3.7 & 7.0 & 89.2 & 0.0 \\
\hline & 8 & 7.6 & 8.6 & 83.7 & 0.0 \\
\hline
\end{tabular}

Notes: Each entry is the percentage of the variance forecast at the specified forecast horizon. Bold values for the 4- and 8 -quarter horizons are used to indicate the relevant policy horizons for inflation and output growth.

In regime 2, the variance decomposition of output growth at the 4-quarter horizon is only marginally smaller than that reported in Table 4, suggesting that most of the variation is due to the monetary policy shock itself. Similarly, the decomposition of the innovation in the policy shock rate is slightly larger for inflation at the 8-quarter horizon than in Table 4, suggesting that some small effects of the policy shock have been partly offset by the regime-dependent dynamics. However, the variance decompositions for innovations in output growth and inflation on the policy rate are much smaller than the variance decompositions reported in Table 4 for policy-dependent responses. The decompositions for innovations in output growth and inflation on the policy rate in Table 5 for regime 2 suggest that the propagation of innovations in output growth and inflation are about one-third the size of those reported in Table 4. This is not surprising since monetary policy responded aggressively to the effects of the relatively large oil-price shocks of the 1970s and the 'great inflation' in the early-1980s.

\section{Concluding remarks and interpretation}

The Markov-switching VAR used in this study identifies two continuous macroeconomic regimes largely due to the variances of output growth, inflation, and the monetary policy rate. Unlike most of the previous research, the empirical results identify important non-linear regime dynamics for the systematic responses of monetary policy. The pre-target regime includes the 1972-to-1995 period and the target regime includes the 1996-to-2010 period. The stochastic division of the sample basically corresponds to the period of explicit-inflation targeting in Canada that began in 1991. The later timing of the target regime is interpreted as the monetary transmission mechanism adapting to the environment of lower volatility of the macroeconomy that was eventually associated with the explicit inflation targets.

The empirical results in Tables 2 and 3 indicate relatively large differences in both the innovation process due to the variance component of the VAR and the propagation mechanism due to the regime-dependent systematic component. In particular, the pre-target regime 2 corresponds to much larger variances for output growth, inflation, and the monetary policy rate, and consequently, has much larger innovations or shocks for these variables. Also, the regime-dependent impulse responses of output growth and inflation to the monetary policy rate are significantly larger in this regime, with the systematic response coefficients to innovations in output growth being about three times larger than in the target 
regime 1. In fact, the policy effects in the inflation equation for the target regime 1 are negligible and the coefficients on systematic responses of the policy rate to inflation are insignificant. Overall, the larger systematic monetary response to output growth and inflation, suggests a stronger monetary transmission mechanism in the pre-target regime 2 .

However, the variance decomposition in Table 4 for the monetary policy response to output growth at the 4-quarter horizon in the target regime 1 indicates that the systematic response explains about 50 per cent of the variation in the policy rate, which is more than three times larger than the response in pre-target regime 2 . The decompositions for inflation suggest that the policy responses have been about the same in the two regimes. Counterfactual analysis in Table 5 suggests that about 35 per cent of the policy response to output growth in the current regime 1 can be explained by the size of the size of the output innovation and about 15 per cent can be attribute to the regime-dependent policy response. Similarly, about 20 per cent of the policy response to an inflation innovation can be explained by the size of the innovation and about 10 per cent can be explained by the regime-dependent policy response. In the pre-target regime 2, the counterfactual analysis suggests that the response of the policy rate to innovations in output growth and inflation, that is, the regime-dependent responses, can account for about three times as much of the variations in the policy rate as the innovations in these variables.

One interpretation of the inconsistency of the larger variance decompositions in the target regime 1 relative to the pre-target regime 2 is that as a result of adopting explicit-inflation control targets, monetary policy has become more responsive to fluctuations in output and inflation with the objective of minimizing the variability of output and inflation (Clarida, Gali, and Gertler, 2000). Consequently, it could be that monetary policy itself has come to systematically respond more decisively to economic conditions, thereby moderating the real effects of demand fluctuations. In this case, the change in the responses to monetary shocks would reflect an improvement in the effectiveness of monetary policy. This is consistent with Boivin and Giannoni (2002a) who have observed that the impact of monetary policy shocks in recent studies using vector autoregressions - defined as unexpected exogenous changes in the monetary policy rate - has had a much smaller impact on output and inflation since the beginning of the 1980's, which would be expected to be more important after the adoption of explicit-inflation targets.

In this interpretation, the tighter control on the target variables requires more frequent, but smaller, monetary policy responses that partly compensate for the smaller effects that monetary policy shocks may have had on output and inflation. Consequently, we would expect to observe larger variance decompositions for output growth, since aggregate demand would be the primary focus of monetary policy. Similarly, we would not expect systematic relationships to develop between inflation and the policy rate, since monetary policy would normally respond to inflation through a Phillips-curve type relationship, reacting to changes in the output growth or the output gap. In this case, monetary policy would not normally need to react directly to inflation shocks. Thus, we would expect to observe precisely a reduction in the variability of target variables due to both smaller monetary policy innovations and systematic policy responses, and hence, an overall tighter monetary transmission mechanism.

The structural VAR model estimated in this study relied on a recursive identification scheme to identify monetary policy, so that the matrix $A_{i}$ is lower triangle and exactly identified, as in Christiano, Eichenbaum, and Evans (1996). Further research should explore alternative identification schemes for monetary policy, such as in the study of the EMU by Rubio-Ramírez, Waggoner, and Zha (2005), which uses a small-scale, open economy VAR similar to the one used in this study. For example, instead of short-run restrictions, Blanchard and Quah (1993) use restrictions on the long-run impulse responses to achieve exact identification of an SVAR. Galí (1992) suggests a combination of contemporaneous and long-run restrictions on impulse responses to identify a SVAR. Gordon and Leeper (1994) and Sims and Zha (2006) propose a non-recursive identification scheme that captures the simultaneous relationships between financial variables, such as the interest rate and money.

Also, the interpretation above of the relatively larger variance decompositions for responses of the monetary policy rate to innovations in output growth and inflation assumes a change in the policy rule used by the central bank in the target regime. However, the analysis in this study did not disentangle whether the tighter responses of monetary policy to output growth and inflation are due to the more stabilizing behaviour of monetary policy or to a change in the functioning of the economy itself. Consequently, this issue requires further research with a structural model that can account for changes in both the behaviour of private economic agents and the policy rule used by the central bank, as suggested by Boivin and Giannoni (2002b).

\section{Acknowledgement}

The excellent research assistance for this manuscript by Maxine LeBreton of Laurentian University is gratefully appreciated. 


\section{References}

Ang, A., \& Bekaert, G. (2002). Regime switches in interest rates. The Journal of Business and Economics, 20, $163-182$. http://dx.doi.org/10.3386/w6508

Armour, J., Engert, W., \& Fung, B. (1996). Overnight innovations as a measure of monetary policy shocks in vector autoregressions. Bank of Canada Working Paper, 96-4.

Bernanke, B., \& Mihov, I. (1998). Measuring monetary policy. The Quarterly Review of Economics, 113, 869-902. http://dx.doi.org/10.3386/w5145

Blanchard, O., \& Quah, D. (1989). The dynamic effects of aggregate demand and supply disturbances. The American Economic Review, 79, 655-673. http://dx.doi.org/10.3386/w2737

Boivin, J., \& Giannoni, M. (2002a). Assessing changes in the monetary transmission mechanism: A VAR approach. Federal Reserve Bank of New York, Economic Policy Review, May 97-111.

Boivin, J., \& Giannoni, M. (2002b). Has monetary policy become less powerful?. Federal Reserve Bank of New York Staff Reports, 144.

Chen, S. (2006). Revisiting the interest rate-exchange rate nexus: a Markov-switching approach. The Journal of Development Economics, 79, 208-224. http://dx.doi.org/10.1016/j.jdeveco.2004.11.003

Christiano, L., Eichenbaum, M., \& Evans, C. (1999). Monetary policy shocks: What have we learned and to what end?, Handbook of Macroeconomics, eds M. Woodford and J. Taylor, North Holland.

Christiano, L.J., Eichenbaum, M., \& Evans, C. (2005). Nominal rigidities and the dynamic effects of a shock to monetary policy. The Journal of Political Economy, 113, 1-45. http://dx.doi.org/10.1016/j.red.2010.01.001

Clarida, R., Gali, J., \& Gertler, M. ( 2000). Monetary policy rules and macroeconomic stability: evidence and theory. The Quarterly Review of Economics, 115,147-180. http://dx.doi.org/10.1162/003355300554692

Ehrmann, M., Ellison, M., \& Vallac, V. (2001). Regime-dependent impulse response functions in a Markov switching vector autoregression model. Bank of Finland Discussion Papers, 11.

Ehrmann, M., Ellison, M., \& Vallac. V. (2003). Regime-dependent impulse response functions in a Markov switching vector autoregression model. Economic Letters, 78, 295-299. http://dx.doi.org/10.1016/S0165-1765(02)00256-2

Fujiwara, I. (2003). Has the effect of monetary policy changed during 1990s?. Osaka School of International Public Policy, Discussion Paper 03-08.

Fujiwara, I. (2006). Evaluating monetary policy when nominal interest rates are almost zero. The Journal of the Japanese and International Economies, 20, 434-453. http://dx.doi:10.1016/j.jjie.2006.02.001

GALÍ, J. (1992). How well Does the IS-LM Model fit postwar U.S. data?. The Quarterly Journal of Economics, 107, 709-738. http://dx.doi.org/10.2307/2118487

Gelfand, A., \& Smith, A. (1990). Sampling-based approaches to calculating marginal densities. The Journal of the American Statistical Association, 85, 398-409.

Girardin, E., \& Moussa. Z. (2009). The effectiveness of quantitative easing in Japan: New evidence from a structural factor-augmented VAR, mimeo, http://www.edge-page.net/jamb2008/ Papers/MoussaEDGE2008.pdf

Gonzalez, A., \& Garcia, J. (2006). Structural changes in the transmission mechanism of monetary Policy in Mexico: A non-linear VAR approach. Bank of Mexico Working Paper 2006-06

Gordon, D. B., \& Leeper, E. M. (1994). The dynamic impacts of monetary policy: An exercise in tentative identification. The Journal of Political Economy, 102, 1228-1247. http://www.jstor.org/stable/2138785

Hamilton, J. (1989). A new approach to the econometric analysis of nonstationary times series and business cycles. Econometrica , 57, 357-84. http://www.jstor.org/stable/1912559

Hamilton, J. (1990). Analysis of time series subject to change in regime. The Journal of Econometrics, 45, 39-70. http://dx.doi:10.1016/0304-4076(90)90093-9

Herwartz, H., \& Lutkepohl, H. (2014). Structural vector autoregressions with Markov-Switching: Combining conventional with statistical identification of shocks. Journal of Econometrics, 183, 104-116. http://dx.doi:10.1016/j.jeconom.2014.06.012

Hubrich, K., \& Tetlow, R. (2015). Financial Stress and Economic Dynamics: The transmission of crises. Journal of Monetary Economics, 70, 100-115. http://dx.doi:10.1016/j.jmoneco.2014.09.005 
King, R., Plosser, C, Stock, J. H., \& Watson, M.(1991). Stochastic trends and economic fluctuations. The American Economic Review, 81, 819-840. http://dx.doi.org/10.3386/w2229

Krolzig, H. (1997). Markov Switching Vector Autoregressions: Modelling, Statistical Inference and Applications to Business Cycle Analysis. Berlin: Springer-Veriag.

Krolzig, H. (2001). Business cycle measurement in the presence of structural change: international evidence. The International Journal of Forecasting, 17, 349-368. http://dx.doi.org/10.1016/S0169-2070(01)00099-1

Krolzig, H., \& Toro, J. (2005). Classical and modern business cycle measurement: the European case. The Spanish Economic Review, 7, 1-21. http://dx.doi.org/10.1007/s10108-004-0088-0

Lange, R. (2013). Monetary policy reactions and the exchange rate: a regime-switching structural VAR for Canada. The International Review of Applied Economics, 27, 612-632. http://dx.doi.org/10.1080/02692171.2012.752446

Paolillo, R. M., \& Petragallo, N. (2004). Asymmetries of monetary policy transmission between US and Euro area, mimeo, http://www.cass.city.ac.uk/data/assets/pdf_file/0005/65174/PaolilloPetragallo.pdf

Sims, C. (1980). Macroeconomics and reality. Econometrica, 48, 1-48. http://www.jstor.org/stable/1912017

Sims, C., Stock, J., \& Watson, M. (1990). Inference in linear time series models with some unit roots. Econometrica, 58, 113-144. http://www.jstor.org/stable/2938337

Sims, C., \& Zha, Z. (2006). Are there regime switches in US monetary policy?. The American Economic Review, 96, 54-81. http://www.jstor.org/stable/30034354

Rubio-Ramírez, Waggoner, J-F, D., \& Zha, T. (2005). Markov-switching structural vector autoregressions: Theory and application. Federal Reserve Bank of Atlanta, Working Paper 2005-27

Smets, F., \& Wouters, R. (2002). An estimated dynamic stochastic general equilibrium model of the Euro area. The Journal of the European Economic Association, 1, 1123-1175. http://dx.doi.org/10.1162/154247603770383415

Soledad, M., \& Martinez, P. (2002). A regime-switching approach to the study of speculative attacks: a focus on EMs crises. Empirical Economics , 27, 299-334.

\section{(cc) $\mathrm{Br}$}

This work is licensed under a Creative Commons Attribution 3.0 License. 